\title{
Prevalence of diabetes mellitus as obtained by nationwide screening in urban areas of Bangladesh
}

\author{
M MOSTAFA ZAMAN, ${ }^{1}$ OMAR ALI SARKAR, ${ }^{2}$ MOHAMMAD MONIRUZZAMAN, ${ }^{1}$ MOKHLESUR RAHMAN ${ }^{3}$
}

1 Noncommunicable Disease Unit, World Health Organization (WHO) Country Office for Bangladesh, Dhaka, Bangladesh

2 Noncommunicable Disease Control Unit, Director General of Health Services, Ministry of Health and Family Welfare, Dhaka, Bangladesh

3 Bureau of Health Education, Director General of Health Services, Ministry of Health and Family Welfare, Dhaka, Bangladesh

We welcome correspondence and research letters to the journal. Research letters should be no more than 800 words with a maximum of 10 references, one table and/or one figure. These will usually be short reports of interim work or final reports of research that do not warrant a full research paper publication. Letters to the editor relating to any articles published in the Journal Letters should ideally be submitted within 2 months following publication of the article on which the authors wish to comment, and should be no more than 600 words with up to 5 references
Key words: prevalence, type 2 diabetes mellitus, diabetes screening, early detection

Asia, including Bangladesh, is in the grip of a diabetes epidemic and has become home to the largest diabetic population. ${ }^{1}$ Recent evidence has confirmed that diabetes amplifies the increased risk of premature death from other noncommunicable diseases in these populations. Nonetheless, nationwide data on diabetes is still suboptimal in Bangladesh, especially for those aged 18 years and older. The Demographic and Health Survey data are for those aged 35 years and older. One study recently reported a prevalence of $9.8 \%$ among urban adults for those aged 18 years and older. ${ }^{2}$ Most other reports for this age group are fragmented and done on a smaller scale in scattered places.

Given the backdrop, we have carried out a nationwide screening - but based in urban locations - of diabetes using random capillary blood glucose among adults aged 18 years and older. For this purpose, we have trained 64 medical officers in blood glucose screening procedures and recording of data on a prescribed form. They were selected from all the 64 district level health managers' (civil surgeons) office responsible for their respective districts. Also, 64 health education officers from 64 districts were trained for campaigning and helping the medical officers to organise screening camps. Educational materials for these pieces of training were provided by the Bureau of Health Education, a central agency of the Ministry of Health and Family Welfare dedicated to the health education and promotion of the people in Bangladesh.

We set up a total of 256 diabetes screening camps ( $4 \times 64$ districts) at the premises of medical college hospitals or district (Sadar) hospitals on World Health Day, 7 April 2016. The theme of the Day was diabetes. We distributed flyers and, using hand-microphones, announced the free measurement of capillary blood glucose from the morning hours and until noon. We targeted a total of 13,600 volunteers to participate (50 $\times 256$ camps $=12,800$ plus an additional 800 participants from the Dhaka district because of its large population). Finally, 13,564 people were screened.

During the screening we collected and recorded information for each participant such as age, sex, history of blood glucose measurement and treatment of diabetes. Glucose measurements were done by laboratory technologists under the supervision of medical officers using Accuchek $^{\circledR}$ glucometers and strips of single batch all over the country. Measurements were done irrespective of prandial status.

Table 1 shows a summary of the blood glucose screening in all 64 districts of Bangladesh on World Health Day, 7 May 2016. Of the 13,564 participants, 8,650 (63.8\%) were men. The mean age of the participants was 41.9 years (men, 43.0 years; women, 39.7 years) with a standard deviation of 11.9 years. Only $29.3 \%$ of the participants had lifetime measurement of blood glucose, and doctors told $13.1 \%$ that they had had diabetes. Antidiabetes medication had been used by $11.6 \%$.

Based on the capillary casual blood glucose cut-off point of $11.1 \mathrm{mmol} / \mathrm{L},{ }^{3}$ the age-standardised (to the latest census population of Bangladesh of 2011) prevalence of diabetes was $7.5 \%$. However, considering either high blood glucose or medication history, the prevalence was $14.2 \%$. An impressive proportion (89.0\%) of known persons with diabetes was receiving medication. However, the control was not that tight. Only $61.7 \%$ had a glucose level $<11.1$ $\mathrm{mmol} / \mathrm{L}$. Additionally, some of them might have been in fasting status and, for these, the cut-off point for diabetes control is much lower. Gener- 
Table 1 Prevalence* of diabetes among voluntary participants of blood glucose screening in all 64 districts of Bangladesh, World Health Day, 7 May 2016

\begin{tabular}{|c|c|c|c|c|c|c|c|c|c|}
\hline $\begin{array}{l}\text { Age } \\
\text { groups, } \\
\text { years }\end{array}$ & $\begin{array}{l}\text { No (\%) of } \\
\text { subjects }\end{array}$ & $\begin{array}{l}\text { Lifetime } \\
\text { measurement } \\
\text { of blood } \\
\text { glucose }\end{array}$ & $\begin{array}{l}\text { Known } \\
\text { person with } \\
\text { diabetes } \\
\text { (as told } \\
\text { by doctor) }\end{array}$ & $\begin{array}{l}\text { On medication } \\
\text { for diabetes } \\
\text { control }\end{array}$ & $\begin{array}{l}\text { Mean (SD) } \\
\text { capillary } \\
\text { blood } \\
\text { glucose, } \\
\text { mmol/L }\end{array}$ & $\begin{array}{l}\text { Capillary } \\
\text { blood } \\
\text { glucose } \\
\geq 11.1 \mathrm{mmol} / \mathrm{L}\end{array}$ & $\begin{array}{l}\text { Blood } \\
\text { glucose } \\
\geq 11.1 \mathrm{mmol} / \mathrm{L} \\
\text { or medication }\end{array}$ & $\begin{array}{l}\text { Newly } \\
\text { detected } \\
\text { diabetes }\end{array}$ & $\begin{array}{l}\text { Control status } \\
\text { of those on } \\
\text { medication } \\
\text { (blood glucose } \\
<11.1 \mathrm{mmol} / \mathrm{L} \text { )‡ }\end{array}$ \\
\hline \multicolumn{10}{|l|}{ Men } \\
\hline $18-24$ & $363(48.2)$ & $38(10.5)$ & $6(1.7)$ & $4(1.1)$ & $5.2(1.5)$ & $2(0.6)$ & $4(1.1)$ & 0 & $2(50.0)$ \\
\hline $25-34$ & 1641 (59.3) & 389 (23.7) & $81(4.9)$ & $71(4.3)$ & $5.9(2.4)$ & $54(3.3)$ & $101(6.1)$ & $30(1.8)$ & $47(66.2)$ \\
\hline $35-44$ & 2237 (59.9) & 839 (37.5) & $360(16.1)$ & 311 (13.9) & $6.8(3.2)$ & $218(9.7)$ & $383(17.1)$ & $72(3.2)$ & 165 (53.1) \\
\hline $45-54$ & 2635 (67.1) & $1294(49.1)$ & 705 (26.8) & 627 (23.8) & $7.6(3.9)$ & 382 (14.5) & $724(27.5)$ & $97(3.7)$ & 342 (54.5) \\
\hline $55-64$ & 1365 (75.6) & 718 (52.6) & 433 (31.7) & 393 (28.8) & $8.1(4.2)$ & 249 (18.2) & 465 (34.1) & $72(5.2)$ & $216(55.0)$ \\
\hline $65+$ & 409 (71.2) & $181(44.2)$ & $133(32.6)$ & $117(28.6)$ & $7.6(3.8)$ & 65 (13.8) & $132(32.3)$ & $15(3.7)$ & 67 (57.3) \\
\hline All (crude) & $8650(63.8)$ & $3459(40.0)$ & 1718 (19.9) & $1523(17.6)$ & $7.1(3.6)$ & $970(11.2)$ & 1809 (20.9) & $286(3.3)$ & 839 (55.1) \\
\hline All (adjustedt) & & 28.9 & 12.4 & 10.8 & & 6.8 & 13.0 & 2.1 & 56.3 \\
\hline \multicolumn{10}{|l|}{ Women } \\
\hline $18-24$ & 389 (51.7) & $37(9.5)$ & $9(2.3)$ & $9(2.3)$ & $5.1(1.6)$ & $6(1.5)$ & $13(3.3)$ & $4(1.0)$ & $7(77.8)$ \\
\hline $25-34$ & $1126(40.7)$ & 322 (28.6) & $100(8.9)$ & $86(7.6)$ & $5.8(2.3)$ & $50(4.4)$ & $109(9.7)$ & $23(2.0)$ & $59(68.6)$ \\
\hline $35-44$ & $1500(40.1)$ & $533(35.5)$ & $246(16.4)$ & $220(14.7)$ & $6.9(3.5)$ & $158(10.8)$ & $270(18.0)$ & $50(3.3)$ & $112(50.9)$ \\
\hline $45-54$ & $1294(32.9)$ & $569(44.0)$ & $336(26.0)$ & $314(24.3)$ & $7.5(4.0)$ & $198(15.3)$ & $368(28.4)$ & $54(4.2)$ & $170(54.1)$ \\
\hline $55-64$ & $440(24.4)$ & 193 (43.9) & $120(27.2)$ & $103(23.4)$ & $7.8(4.4)$ & 65 (14.3) & $124(28.2)$ & $21(4.8)$ & $59(57.3)$ \\
\hline $65+$ & $165(28.7)$ & $61(37.0)$ & $33(20.0)$ & $30(18.2)$ & $7.4(4)$ & $24(14.5)$ & $41(24.8)$ & $11(6.7)$ & $17(56.7)$ \\
\hline All (crude) & $4914(36.2)$ & $1715(34.9)$ & $844(17.2)$ & 762 (15.5) & $6.8(3.5)$ & $501(10.2)$ & $925(18.8)$ & $163(3.3)$ & $424(55.6)$ \\
\hline All (adjustedt) & & 29.0 & 13.4 & 12.0 & & 8.0 & 14.9 & 2.9 & 63.7 \\
\hline \multicolumn{10}{|l|}{ Both sexes } \\
\hline $18-24$ & $752(5.5)$ & 75 (10.0) & $15(2.0)$ & $13(1.7)$ & $5.1(1.6)$ & $8(1.1)$ & $17(2.3)$ & $4(0.5)$ & $9(69.2)$ \\
\hline $25-34$ & $2767(20.4)$ & $711(25.7)$ & $181(6.5)$ & $157(5.5)$ & $5.8(2.3)$ & $104(3.8)$ & $210(7.6)$ & $53(1.9)$ & 106 (67.5) \\
\hline $35-44$ & 3737 (27.5) & $1372(36.7)$ & $606(16.2)$ & $531(14.2)$ & $6.8(3.3)$ & $376(10.1)$ & $653(17.5)$ & $122(3.3)$ & $277(52.2)$ \\
\hline $45-54$ & 3929 (29.0) & $1863(47.4)$ & $1041(26.5)$ & 941 (23.9) & $7.6(4.0)$ & $580(14.7)$ & $1092(27.8)$ & $151(3.8)$ & $512(54.4)$ \\
\hline $55-64$ & 1805 (13.3) & $911(50.5)$ & $553(30.6)$ & 496 (27.5) & $8.0(4.3)$ & $314(17.4)$ & $589(32.6)$ & $93(5.1)$ & $275(55.4)$ \\
\hline $65+$ & $574(4.2)$ & $242(42.2)$ & $166(28.9)$ & $147(25.6)$ & $7.6(3.9)$ & 89 (15.5) & $173(30.1)$ & $26(4.5)$ & $84(57.1)$ \\
\hline All (crude) & $13564(100.0)$ & $5174(38.1)$ & $2562(18.9)$ & $2285(16.8)$ & $6.9(3.5)$ & $1471(10.8)$ & $2734(20.2)$ & 449 (3.3) & $1263(55.3)$ \\
\hline All (adjustedt) & & 29.3 & 13.1 & 11.6 & & 7.5 & 14.2 & 2.5 & 61.7 \\
\hline
\end{tabular}

ally, awareness and control of diabetes is poor in Bangladeshi adults, perhaps due to low education and low economic status. ${ }^{4}$

These blood glucose testing camps in all major urban areas of Bangladesh could bring an additional $2.5 \%$ of people (from the base of 13,564 participants) whose diabetes status was unknown. This percentage appears to be small, but can be considered promising compared with a somewhat similar screening campaign in Saudi Arabia that identified $1.8 \%$ of newly diagnosed cases of diabetes. ${ }^{5}$

There is hardly any national level screening for diabetes in Bangladesh with which to compare our data, but our age-standardised prevalence of $14.2 \%$ was on the higher side compared with the reported prevalence in the urban population of $9.8 \%$ for the same age group. ${ }^{2}$ Our screening was done only in urban areas and in tertiary level hospital premises, where some of the participants might have come to the hospital for diagnostic services. Therefore, our results may not represent the general population, and the population resides in rural areas. We used a casual blood glucose level of $\geq 11.1 \mathrm{mmol} / \mathrm{L}$, in the absence of classic symptoms,

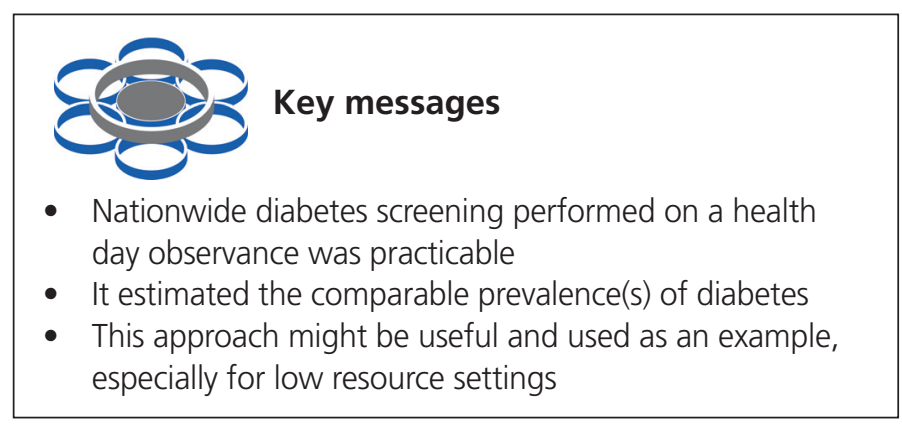

for labelling diabetes in this study. ${ }^{3}$ However, some participants, as mentioned earlier, might have been in fasting status, which may have compensated this issue. Moreover, more people with diabetes might have volunteered for blood glucose testing compared with their healthy counterparts leading to a higher prevalence of diabetes. Organising screening camps in public places other than hospital premises could potentially minimise these limitations and make estimates more representative. 
Conflict of interest None declared. The authors alone are responsible for the views expressed in this article, which do not necessarily represent the views, decisions or policies of the institutions with which they are affiliated.

Funding World Health Organization (WHO) provided the funds and technical assistance through a DFC Agreement No. 2016/611054-0/PO\#201450238

Acknowledgements We sincerely thank Dr Syed Mahfuzul Huq, Mr Reazwanul Haque Khan and Ms Suraiya Akter for their support in the training of people and supporting the field execution. Special thanks to Mr Reazwanul Haque Khan for the preparation of the table.

\section{References}

1. Hills $A P$, Arena R, Khunti $K$, et al. Epidemiology and determinants of type 2 diabetes in south Asia. Lancet Diabetes Endocrinol 2018;6(12):966-78. https://doi.org/10.1016/s2213-8587(18)30204-3

2. Islam JY, Zaman MM, Bhuiyan MR, Haq SA, Ahmed S, Al-Qadir AZ. Prevalence and determinants of hyperglycaemia among adults in Bangladesh: results from a population-based national survey. BMJ Open 2019; 9(7):e029674. http://dx.doi.org/10.1136/bmjopen-2019-029674
3. Engelgau MM, Narayan KM, Herman WH. Screening for type 2 diabetes. Diabetes Care 2000;23(10):1563-80. https://doi.org/10.2337/diacare. 23.10.1563

4. Rahman MS, Akter S, Abe SK, et al. Awareness, treatment, and control of diabetes in Bangladesh: a nationwide population-based study. PloS One 2015;10(2):e0118365. https://doi.org/10.1371/journal.pone.0118365

5. Al-Baghli NA, Al-Ghamdi AJ, Al-Turki KA, Al Elq AH, El-Zubaier AG, Bahnassy A. Prevalence of diabetes mellitus and impaired fasting glucose levels in the Eastern Province of Saudi Arabia: results of a screening campaign. Singapore Med J 2010;51(12):923-30. https://www.ncbi.nlm.nih.gov/ pubmed/21221496

Correspondence: Mohammad Moniruzzaman Department of Public Health, Shiga University of Medical Science, Seta Tsukinowa-cho, Otsu, Shiga, 520-2192, Japan Tel: +81-80-9820-7564 E-mail:mmzbd82@gmail.com

Br J Diabetes 2020:20:58-60 https://doi.org/10.15277/bjd.2020.244 